\title{
Swastik (A Hindu Symbol) as a Multiband Metamaterial unit-cell
}

\author{
Alok Pandey \\ Department of Electronics and Communication Engineering \\ Poornima University, Jaipur, Rajasthan, India \\ Pravesh Chaudhary \\ Department of Physics \\ Poornima University, Jaipur, Rajasthan, India \\ Santosh Agrahari \\ Department of Electronics and Communication Engineering \\ Poornima University, Jaipur, Rajasthan, India
}

\begin{abstract}
In this paper, we designed a novel metamaterial unit-cell and analyze it with different orientation. The unitcell is based on a hindu mythological symbol called swastik pattern and operates at the frequency range from 0.1 to 4.2 GHz and 4.7 to 5.8 GHz. The proposed structure offers a dual band metamaterial behavior and at the same time provides wide band metamaterial unit-cells. The hindu mythological symbol swastik unit-cell is first simulated and its $\mathrm{S}$ parameters are calculated and then by changing its orientation we see the effects on its s-parameters In this paper we have used three different geometries of same dimension of unit cell.
\end{abstract}

Keywords - Metamaterial, Multiband, Unit-cell.

\section{INTRODUCTION}

From the time near the beginning of realization of metamaterials [1-2], a variety of geometries have been used as metamaterial unit-cells. Some of well known unit cells are like double split-ring resonators (DSR), broadsidecoupled SRRs (BC-SRR) and spiral resonators. [3-6]. Maximum type of unit cells offers a single resonant frequency or single band metamaterial response. When we have an application of multi-band antenna, such as cell phones, beam forming antenna, single resonant metamaterial is an issue. To solve this problem, various multiband unit cells are proposed in the literature such as the work reported in [7-9]. In these structures several bands are obtained by using single repeating geometry with different sizes. However, they need to be implemented on a high-epsilon substrate. Moreover, they cannot benefit from the entire surface of the substrate because repeating a geometry in a small scale requires high-precision fabrication techniques. Here, a special design called the mythological symbol swastik pattern is used as a metamaterial unit-cell. The swastika is a very old spiritual symbol used in the Indian subcontinent, East Asia and Southeast Asia. It is also a historic symbol found in almost every culture with different significance. Here we are using these structures in multiband metamaterial applications. In this paper, the swastik structure is first simulated and then the effective constitutive parameters i.e. $\varepsilon r, \mu_{\mathrm{r}}$ and the effective refractive index are extracted from the S-parameters using a well-known algorithm explained in [12]. According to the results, it is proved that this unit-cell shows a wide-band metamaterial behavior over the frequency range of 1 to $4.2 \mathrm{GHz}$. The hindu mythological symbol swastik unit-cell is first simulated and its S-parameters are calculated and then by changing its orientation we see the effects on its sparameters. In this paper we have used three different geometries of same dimension of unit cell. Our unit-cell is printed on a low-epsilon substrate such as FR4 Epoxy with $\quad \varepsilon r=4.4$ and the dimension of the substrate is $15 \mathrm{x}$ $15 \mathrm{~mm}$.

\section{THE UNIT-CELL GEOMETRY}

Fig. 1 shows the geometry of the proposed unit-cell. The swastika is an ancient religious symbol used in the Indian subcontinent, East Asia and Southeast Asia. It is also a historic symbol found in almost every culture with different 
significance. Here, the proposed swastik unit-cell is designed on a FR4 epoxy substrate with the relative permittivity of $\varepsilon r=4.4$ and the thickness of the substrate is $0.4 \mathrm{~mm}$. The dimensions of the structure as follows; $\mathrm{a}=4.3 \mathrm{~mm}, \mathrm{~b}=0.6$ $\mathrm{mm}, \mathrm{c}=3.7 \mathrm{~mm}$ and $\mathrm{d}=8 \mathrm{~mm}$. substrate have a dimension of $15 \times 15 \mathrm{~mm}$ as show in Fig.1. resonators are made of copper lines with the metal thickness of $0.03 \mathrm{~mm}$ and conductivity of $5.8 \times 10^{7} \mathrm{~S} / \mathrm{m}$.

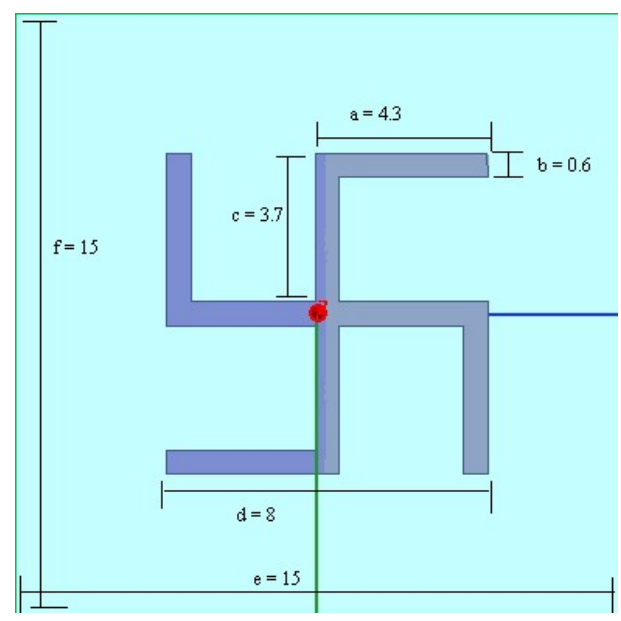

Fig.1 Swastik pattern unit cell with dimension $\mathrm{a}=4.3 \mathrm{~mm}, \mathrm{~b}=0.6 \mathrm{~mm}, \mathrm{c}=3.7 \mathrm{~mm}$ and $\mathrm{d}=8 \mathrm{~mm}$. substrate have a dimension of $15 \mathrm{x} 15 \mathrm{~mm}$.

\section{SimULATION AND RESULTS}

The simulation work was done on HFSS Software the metamaterial structure unit cell is covered by the air box the $\mathrm{x}$ polarized incident electromagnetic plane wave propagates along the z- direction. Hence, the direction of the magnetic field vector is along the $\mathrm{z}$ axis that is perpendicular to the resonator plane.

To analyze the result of array of unit cells two master and two slave boundaries are assign in $\mathrm{x}-\mathrm{z}$ and $\mathrm{y}-\mathrm{z}$ plane as show in Fig.2 (a) and the floquet port is applied for excitation on both boundaries in x-y plane as show in Fig 2 (b). HFSS simulations were performed with $0.02 \mathrm{GHz}$ incremental steps. Using a single unit cell together with the boundary conditions stated above, one can model an infinite periodic array of structures as discussed in [5].
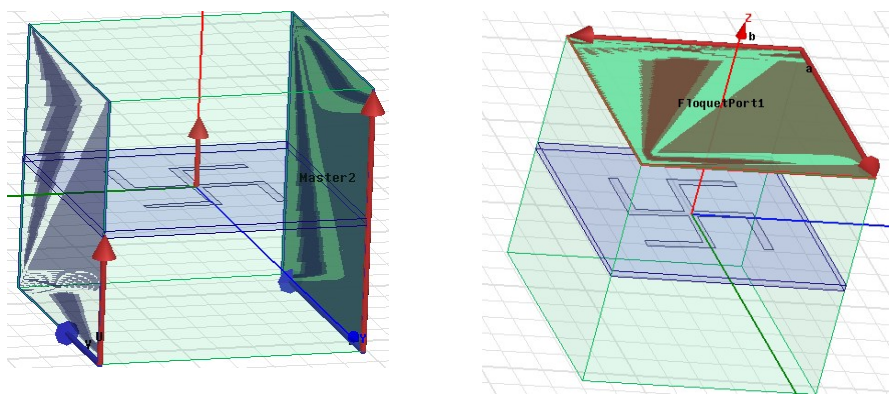

Fig.2 Boundaries and excitation assign to unit cell. 


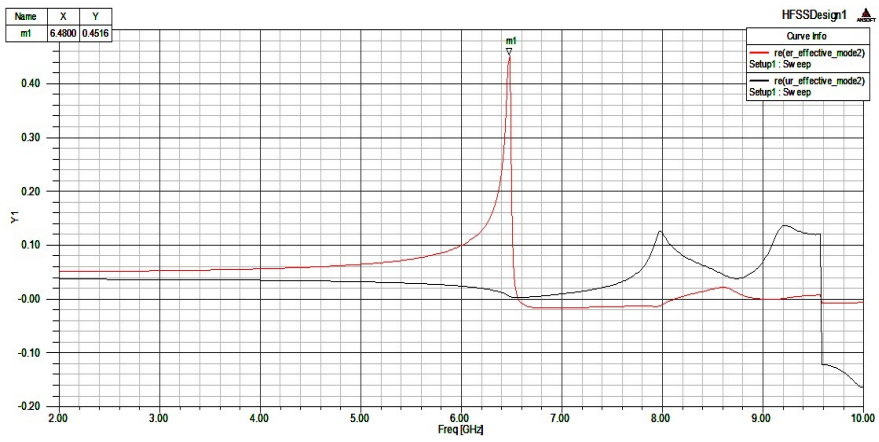

Fig.3 Refractive index for swastika symbol.

Fig.3 shows the real value of permittivity and permeability of unit cell array and Fig. 4 shows the S11 and S12 parameters of unit cell. It can be easily seen that the SII parameter is blow $-20 \mathrm{~dB}$ from 1 to $4.3 \mathrm{GHz}$ and another resonant frequency is at $5.5 \mathrm{GHz}$. Similarly the value of S12 parameter is less than $-40 \mathrm{~dB}$ at $4.6 \mathrm{GHz}$ and $6.12 \mathrm{GHz}$. Moreover, the number of the resonances also changes when the epsilon is increased. Another means of tuning the resonance frequency of the unit-cell could be modifying the line width. Effect of this parameter is shown in [10].

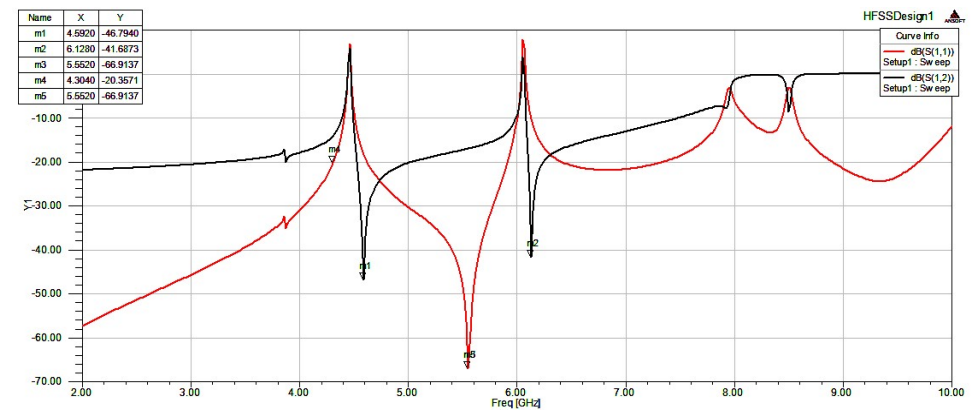

Fig.4 S11 and S12 parameters for swastika symbol

IV. COMPARISION OF VARIOUS ORIENTATION OF UNIT CELL

By changing the orientation of unit cell we have observed some more results of Swastik pattern unit cell. The basic design and dimensions of unit cell is shown in fig.1. In the next design we have rotate the unit cell by 45 degree in clockwise direction and in the another design we have insert a thin wire at the bottom of the unit cell. The dimension of the thin wire is $0.5 \mathrm{~mm}$ and rest of the dimensions is same as design 1. Both of the designs i.e. clockwise rotated and with thin wire are shown in Fig 5 and Fig 6 respectively.

Perfect electric conductor (PEC) boundary conditions are applied along the boundaries in xz plane and perfect magnetic conductor (PMC) boundary conditions are applied along the boundaries in xy plane. The remaining two boundaries are assigned to be the input-output wave ports. Sweep type is interpolating and 501 linear counts are used in HFSS simulation. Maximum numbers of passes are 15 with 0.02 delta velue. 


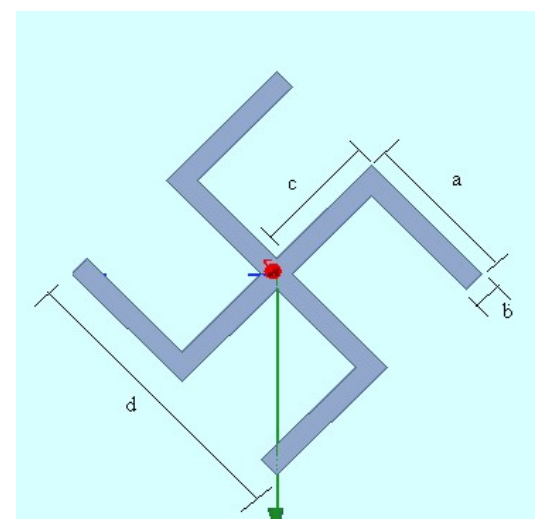

Fig. 5 Swastik pattern unit cell with $45^{\circ}$ rotation. dimension $\mathrm{a}=4.3 \mathrm{~mm}, \mathrm{~b}=0.6 \mathrm{~mm}, \mathrm{c}=3.7 \mathrm{~mm}$ and $\mathrm{d}=8 \mathrm{~mm}$. substrate have a dimension of $15 \mathrm{x}$ $15 \mathrm{~mm}$.

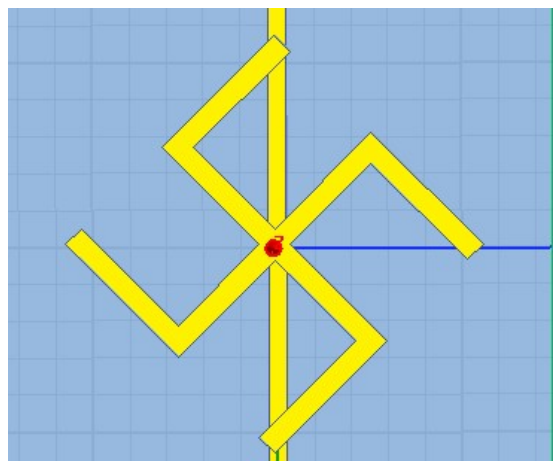

Fig.6 Swastik pattern unit cell with $45{ }^{\circ}$ rotation

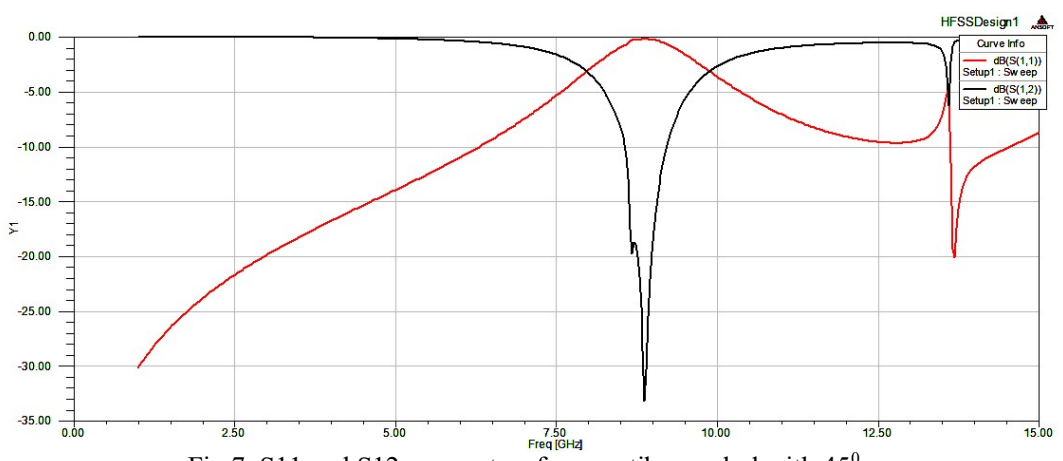

Fig.7. S11 and S12 parameters for swastika symbol with $45^{\circ}$

By seeing the Fig. 7 and Fig. 8 we can analyze that if we rotate th symbol by 45 degree clock or anti clockwise or if we add thin wire in the geometry we found change in the resonant frequency as shown in the table.1. 


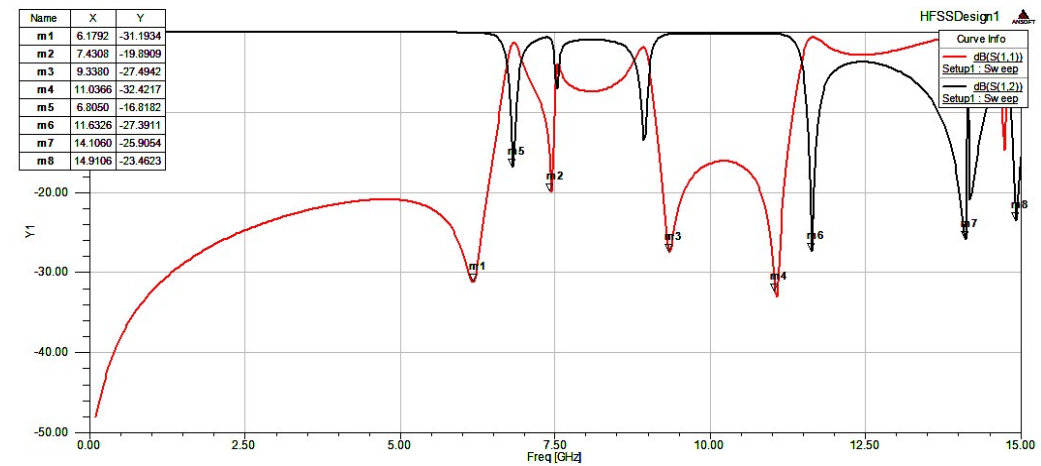

Fig.8. S11 and S12 parameters for swastika symbol with thin wire.

Tale.1 Comparision between various MM unit cells

\begin{tabular}{|c|c|c|c|c|c|}
\hline \multicolumn{2}{|c|}{ Design1 } & \multicolumn{2}{|c|}{ Design.2 } & \multicolumn{2}{|c|}{ Design.3 } \\
\hline S11 & S12 & $\mathrm{S} 11$ & S12 & S11 & S12 \\
\hline $\begin{array}{c}4.3 \\
\mathrm{GHz}\end{array}$ & $\begin{array}{c}4.6 \\
\mathrm{GHz}\end{array}$ & $13.6 \mathrm{GHz}$ & $9 \mathrm{GHz}$ & $0.1-6 \mathrm{GHz}$ & $6.8 \mathrm{GHz}$ \\
\hline \multirow{3}{*}{$\begin{array}{c}5.5 \\
\mathrm{GHz}\end{array}$} & \multirow[t]{3}{*}{$6.12 \mathrm{GHz}$} & & & $7.4 \mathrm{GHz}$ & $11.6 \mathrm{GHz}$ \\
\hline & & & & $9.3 \mathrm{GHz}$ & $14 \mathrm{GHz}$ \\
\hline & & & & $11 \mathrm{GHz}$ & $15 \mathrm{GHz}$ \\
\hline
\end{tabular}

\section{CONCLUSION}

By showing table.1 we can conclude that get only one value one resonant of S11 parameters at $13.6 \mathrm{GHz}$ and S12 parameter at $9 \mathrm{GHz}$. But when we use the thin wire at the bottom part of the cell we find that it is resonant $100 \mathrm{MHz}$ to $6 \mathrm{GHz}$ and other bands are 7.4, 9.3 and $11 \mathrm{GHz}$. S12 parameters are resonant at 6.8, 11.614 and $15 \mathrm{GHz}$.

\section{REFERENCES}

[1] Veselago, V. G., "The electrodynamics of substances with simultaneously negative values of $\varepsilon$ and $\mu$," Sov. Phys. Usp., Vol. 10, 509-514, 1968.

[2] Smith, D. R., W. J. Padilla, D. C. Vier, S. C. Nemat-Nasser,and S. Schultz, "Composite medium with simultaneously negativepermeability and permittivity," Phys. Rev. Lett., Vol. 84, No. 18,4184-4187, 2000.

[3] L. Wang, X. Q. Lin, F. Cheng, Y. Fan and Z. B. Zhou, "Electric Split-Ring Resonator Based on Double-Sided Parallel-Strip Line," IEEE Antenna \& Wireless Propag. Letters.

[4] B. Zarghooni and T. A. Denidni, "New Compact Metamaterial Unit-cell Using SIR Technique," IEEE Lett. Microw. Theory Tech., vol. 24, no. 5 pp. 315-317, May 2014.

[5] R. Marques, F. Mesa, J. Martel and F. Medina, "Comparative Analysis of Edge- and Broadside-Coupled Split Ring Resonators For Metamaterial Design- Theory and Experiments," IEEE Trans. Antennas Propagat., vol. 51, no. 10, Oct. 2003.

[6] J. D. Baena, J. Bonache, F. Martin, R. M. Sillero, F. Falcone, T. Lopetegi, M. A. G. Laso, J Garcia, I. Gil, M. F. Portillo and M. Sorolla, "Equivalent-Circuit Models for Split-Ring Resonators and Complementary Split-Ring Resonators Coupled to Planar Transmission Lines," IEEE Trans. Microw. Theory Tech., vol. 53, no. 4, pp. 1451- 1461, Apr. 2005. 
[7] C. Sabah "Multiband metamaterials based on multiple concentric open ring resonators topology," IEEE Journal of Selected Topics in Quantum

Electronics, vol. 19, 2013.

[8] Baena, J. D., R. Marqu'es, F. Medina, and J. Martel, Artificialmagnetic metamaterial design by using spiral resonators," Phys.Rev. B, Vol. 69, 014402(1)-(5), 2004.

[9] Yurduseven O, Yilmaz AE, Turhan-Sayan G. "Hybrid-shaped singleloop resonator: a four-band metamaterial structure," Electron. Lett. 2011;47:1381-1382.

[10] A. Pandey, P. Chaudhary and M. L. Gupta, "Neural network-based model for optimum design of wired bow-tie antenna," 2015 International Conference on Electrical, Electronics, Signals, Communication and Optimization (EESCO), Visakhapatnam, 2015, pp. 1-2.. 